Research Paper

\title{
Psychological and Behavioral Factors Associated With Academic Performance in Overweight and Obese High School Female Students: A Structural Equation Model
}

\author{
Ameneh Ghartappeh ${ }^{1}$, Mozhgan Arefi ${ }^{1^{*}} \mathrm{O}$, Salar Faramarzi $^{2} \mathrm{O}$, Yahya Pasdar ${ }^{3}$
}

1. Department of Psychology, Isfahan (Khorasgan) Branch, Isfahan, Iran.

2. Department of Psychology and Education of Children with Special Needs, Faculty of Education and Psychology, University of Isfahan, Isfahan, Iran.

3. Department of Nutritional Sciences, Faculty of Nutrition and Food Science, Kermanshah University of Medical Sciences, Kermanshah, Iran.

\begin{tabular}{|c|c|}
\hline $\begin{array}{l}\text { Use your device to scan } \\
\text { and read the article online }\end{array}$ & Citation Ghartappeh A, Arefi M, Faramarzi S, Pasdar Y. Psychological and Behavioral Factors Associated With Academic Perfor- \\
\hline 口ifita & $\begin{array}{l}\text { mance in Overweight and Obese High School Female Students: A Structural Equation Model. Avicenna J of Neuropsychophysiol- } \\
\text { ogy. 2019; 6(4):165-174. http://dx.doi.org/10.32598/ajnpp.6.4.2 }\end{array}$ \\
\hline 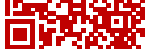 & d ol/http://dx.doi.org/10.32598/ajnpp.6.4.2 \\
\hline
\end{tabular}

\section{(c) 0 (3)}

Article info:

Received: 16 May 2019

Accepted: 25 Aug 2019

Available Online: 01 Nov 2019

Keywords:

Obesity, Academic

performance, Mental health,

Structural equation modeling

\section{A B STRACT}

Background: Obesity in adolescents is associated with not only physical and psychological problems but also a decrease in educational performance.

Objectives: This study aimed at determining the behavioral and psychological factors associated with academic performance in overweight and obese girl students in Kermanshah, Iran.

Materials and Methods: This cross-sectional study was performed on 419 overweight and obese female high school students of Kermanshah in 2017 selected through two-stage cluster sampling. Data were collected using the standard questionnaires, including high school students' academic performance, Rosenberg Self-Esteem Scale, Goldberg's General Health Questionnaire, Littleton's Body Image Concern Inventory, physical activity subscale of Walker's Health-Promoting Lifestyle Profile II, and Pittsburgh Sleep Quality Index. Data analysis for structural equation modeling was performed using the IBM SPSS AMOS V. 21 software.

Results: Self-esteem was found to have significant direct $(\beta=0.412)$ and indirect $(\beta=0.142)$ effects on academic performance, with direct effects being stronger $(\mathrm{P}<0.001)$. Body image, physical activity, general health, and sleep quality were found to have a significant direct effect on academic performance $(P<0.05)$. However, these factors also had a significant indirect effect on this variable through the mediation of general health $(P<0.05)$. Overall, these variables accounted for $35 \%$ of the variance in academic performance.

Conclusion: Self-esteem, body image, physical activity, and sleep quality affect the academic performance of obese and overweight girl high school students not only directly but also indirectly through general health. The results of this study demonstrated the mediating role of mental health in predicting the academic performance of overweight and obese girl students.

\section{* Corresponding Author:}

Mozhgan Arefi, PhD.

Address: Department of Psychology, Isfahan (Khorasgan) Branch, Isfahan, Iran.

Tel: +98 (918) 3336864

E-mail: ghartappeh_a@yahoo.com 


\section{Introduction}

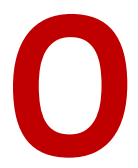

verweight and obesity are among the major health problems threatening our physical and mental health [1]. They are important risk factors for chronic diseases, such as hypertension, diabetes, cardiovascular diseases, and several types of cancers and also are associated with adverse psychological effects, such as body image dissatisfaction, reduced self-esteem, depression, and social exclusion [2]. According to the World Health Organization, there are over one billion overweight and obese people in the world [3]. Iran is among the seven countries with the highest prevalence of obesity [4]. In addition to adults, Iranian children and adolescents are also struggling with problems linked to overweight and obesity as the most common eating disorders in Iranian adolescents, especially girls. The prevalence of overweight and obesity among Iranian adolescent girls has been reported to be 1.23 and 3.8 , respectively [5]

Obese people have a lower Intelligence Quotient (IQ) and exhibit poorer performance, memory, and attention than people with normal weight [6-8]. Academic performance, which means the extent of learning in educational settings [9], plays an important role in academic achievement and is a strong predictor of career and social success in adulthood [10]. It has not yet been established whether obesity affects academic performance directly or as a mediating factor for other causes, such as decreased self-esteem, anxiety, depression, social exclusion, and reduced physical health [11].

Mental health is a state of well-being, in which people realize their abilities to cope with stress [12]. Mental health and overweight are inversely correlated [13]. Furthermore, low mental health is associated with behavioral problems, such as academic failure [14, 15]. Self-esteem refers to one's sense of overall value or worth and value and is another factor that decreases with an increase in body mass index (BMI) [16]. For those with self-esteem more strongly influenced by appearance and acceptance by society, obesity and its unpleasant image can have a more negative impact on self-esteem [17]. Students with higher self-confidence and self-esteem are more successful in school and have higher academic performance [18].

Body image is another factor affecting the academic performance of obese students. Body image is a multidimensional and complex psychological construct that includes one's body-related self-perceptions and self-attitudes, including thoughts, beliefs, feelings, and behaviors [19]. Studies have shown that multiple dimensions of body image are associated with academic performance problems. For example, concerns about height and weight may be the most important factor affecting the relationship between body image and academic achievement $[20,21]$.

Physical fitness and sleep also affect academic performance. Higher physical fitness levels are associated with better learning by improving the basal ganglia function in the brain, which is critical for cognitive processes, and also other parts involved in the language learning process $[22,23]$. Research has shown that poor sleep quality, sleeping late, waking up early in the morning, and disrupted sleep can affect learning capacity, academic performance, and neurobehavioral function [24, 25]. The effects of these factors have not yet been examined on the academic performance of the Iranian obese and overweight students using structural equation models. Considering the effects of obesity on academic performance, as well as the higher prevalence of obesity in Iranian female adolescents compared with males, identifying the factors influencing the academic performance of these students is of great importance. This study aimed at determining the direct and indirect effects of factors associated with academic performance in overweight and obese girl students using structural equation modeling.

\section{Materials and Methods}

\section{Study design}

This correlational study using the structural equation modeling (SEM) was conducted on female students at public high schools in Kermanshah, Iran in 2017. This study was approved by the National Research Ethics Committee of Iran (Code: IR.IAU.KHUUISF. REC.1398.049). Accordingly, two (out of three) education districts of Kermanshah were randomly selected followed by selecting eight schools from each district randomly. Two-stage cluster sampling was used to select the students of each school. According to the SEM design of the study, the needed sample size should be at least 15 times more than the number of observed variables (Hooman, 2005 quoted from Ganji 193) [26]. Therefore, the sample size was estimated at 390 cases. Considering the possibility of incomplete responses, the questionnaires were distributed to 419 students to ensure the adequate sample size. Following referral to the schools, after making necessary coordination with the principals, obese and overweight students who were eligible for the study and were willing to participate 
were identified and the written consent was obtained. Students with a medical condition affecting weight or height (e.g. severe heart, kidney, liver, neurological, digestive, thyroid, rheumatic, and skeletal problems or cancer) were excluded. Students taking supplements or drugs affecting weight or height or those on a specific diet were also excluded.

After sampling, the subjects' height and weight were measured by healthcare professionals. Weight was measured without shoes and with minimal clothing using a CAMRY scale Model EB320 with 100-gram accuracy. Height was also measured with a wall-mounted height gauge with $0.5-\mathrm{cm}$ accuracy. BMI was calculated by dividing the weight $(\mathrm{kg})$ by the square of height $\left(\mathrm{m}^{2}\right)$. Overweight and obesity were determined based on the Centers for Disease Control and Prevention (CDC) classifications. Accordingly, the BMI at the $85^{\text {th }}$ to $94.99^{\text {th }}$ percentiles and a BMI greater than or equal to the 95th percentile can be used to identify children of the same age and gender who are overweight and obese [2].

Other data were collected using a questionnaire. To ensure the confidentiality of information, the questionnaires were given identification codes. After providing the necessary explanations, the questionnaires were completed by the students.

Self-esteem was assessed using the Rosenberg Selfesteem Scale (RSES), which is a 10-item unidimensional scale with two possible answers (agree and disagree), in which higher scores indicate higher self-esteem. The test-retest reliability of this scale for a 3-week interval has been measured as 0.78 [27].

Body image was measured using the Body Image Concern Inventory (BICl) developed by Littleton et al. (2005). This inventory consists of 19 items, which assess the respondents' perception of their body on a 5-point Likert scale from 1 (never) to 5 (always). The reliability of this inventory has been confirmed with Cronbach's alpha of 0.93 and the items correlating with the total score in the range of 0.32 to 0.73 , indicating its acceptable reliability. The validity of $\mathrm{BICl}$ has been confirmed by determining its correlation coefficient through the Body Dysmorphic Disorder Questionnaire $(P<0.01, r=0.83)$ [28].

General health was measured using the General Health Questionnaire designed by Goldberg and Hillier (1979). It consists of 28 items and four subscales of physical symptoms, anxiety, social dysfunction, and depression, which are scored on a 4-point Likert scale (higher scores indicate poorer general health). Using the test-retest, split-half, and Cronbach's alpha methods, the reliability of this questionnaire has been obtained $0.70,0.93$, and $90 \%$, respectively [28]. In the present study, this questionnaire was found with a Cronbach's alpha of 0.83 .

Physical activity was measured using the Health Promoting Lifestyle Profile (HPLPII). The 34-item HPLPII has four subscales of health responsibility ( 9 items), physical activity ( 8 items), nutrition ( 9 items), and stress management ( 8 items). In this study, only Nutrition and Physical Activity subscales of this scale were used. The scale is scored on a 4-point Likert scale (never, sometimes, often, and routinely). The total score of the HPLPII is obtained by averaging the scores of responses given to 34 items. Higher scores indicate a healthier lifestyle. According to the Mohammedian report, HPLPII enjoys a good internal consistency ( $\alpha=0.86)$. The Cronbach's alpha for different domains of this scale has been reported 70\%-77\% [29]. In the present study, Cronbach's alpha of 0.83 was obtained for this scale.

The sleep quality of the students was measured using the Pittsburgh Sleep Quality Index (PSQI). PSQI consists of 19 questions, which are scored on a 4-point Likert scale from 0 to 3 . This questionnaire has seven subscales: 1 . Subjective sleep quality; 2 . Sleep latency; 3. Sleep duration; 4 . Sleep efficiency; 5 . Sleep disturbance; 6. Sleep medication use; and 7. Daytime dysfunction due to sleepiness. The total score of PSQI is the sum of the seven scores of the subscales ranging from 0 to 21 . A total score of more than 6 indicates poor sleep quality. PSQI has been reported with a Cronbach's alpha of $89 \%$ and the validity of $86 \%$ [30]. In the present study, Cronbach's alpha of 0.75 was determined for PSQI.

The academic performance of the students was measured using the standard questionnaire of high school students' academic performance consisting of $60 \mathrm{bi}$ nary questions. The questions $11,12,17,18,20,23$, $24,26,30,32,33,35,38,39,41,44,48,50,51,53$, $54,55,56,57,59$ and 60 are answered by yes (1) or no (0), but other questions have the opposite scoring pattern (yes=0; no=1). In the present study, this questionnaire had a Cronbach's alpha of 0.84 . To obtain the total score of this scale, scores of all questions should be summed together (ranging from 0-60), with higher scores indicating better academic performance and vice versa [31]. In previous studies, Cronbach's alpha of this questionnaire for Iranian students has been reported to be $82 \%$ [31].

The conceptual model of the study was designed through a systematic review of the variables related to the 
academic performance of overweight and obese students. Using this model, the relationships between the many variables affecting academic performance were then developed into a structural equation model (Figure 1).

\section{Data analysis}

Data were analyzed with IBM SPSS AMOS V. 21 software using descriptive statistics (mean, standard deviation, and standard deviation) and analytical statistics (correlation and structural equation modeling). The normality of data was established using the Kolmogorov-Smirnov test and skewness/kurtosis analysis. The variance inflation factor (VIF) was obtained 1.05 for physical activity variables, 1.72 for self-esteem, 1.50 for sleep quality, 1.45 for body image dissatisfaction, and 1.80 for general health. Since the obtained VIF values were less than 3 , there was no significant multicollinearity between the research variables.

SEM was used to evaluate the direct and indirect ef fects of latent and observed variables in the model on the students' academic performance. The Comparative Fit Index (CFI), the Goodness of Fit Index (GFI), and Normed Fit Index (NFI) of greater than 0.90, Root Mean Square Error Of Approximation (RMSEA) of equal to or less than 0.05 , and $\chi^{2} / d f$ in the range of $1-3$ were considered to indicate a good model fit. The structural equation model of the study was validated by the goodness of fit indices typically used for this structural analysis. For the developed model, all goodness of fit indices were higher than 0.90, and RMSEA was 0.039 (Table 1). Model estimations were performed using the Maximum Likelihood Estimation method (MLE). In all analyses, $\mathrm{P}<0.05$ was assumed statistically significant [32].

\section{Results}

A total of 419 girl high school students with a mean age of $16.10 \pm 0.89$ years participated in the study. The mean score of depression was $6.78 \pm 0.03$, the mean score of self-esteem was $3.70 \pm 0.02$, and the mean score of sleep quality was $5.44 \pm 0.14$. Also, the mean score of students' academic performance was $42.55 \pm 0.39$ (Table 2).

All studied variables had a significant correlation at the $P<0.01$ level with academic performance. Self-esteem $(r=0.550)$, stress $(r=-0.466)$ and depression $(r=-0.523)$ were found with strong correlation with academic performance. Physical activity showed the least correlation with academic performance $(r=0.183)$ (Table 3).

The results of SEM analysis showed that physical activity had both direct and indirect effects on students' academic performance; however, its indirect effects were stronger. Self-esteem was also found to have significant direct $(\beta=0.412)$ and indirect $(\beta=0.142)$ effects on academic performance, with direct effects being stronger

Table 1. Goodness of fit indices computed for the developed structural equation model

\begin{tabular}{cccccccc}
\hline$\chi^{2}$ & df & $\chi^{2} / d f$ & RMSEA & GFI & AGFI & NFI & CFI \\
\hline 42.884 & 26 & 1.649 & 0.039 & 0.980 & 0.958 & 0.977 & 0.991 \\
\hline & & & & & & AJNPP
\end{tabular}

Table 2. Descriptive characteristics of the research variables

\begin{tabular}{|c|c|c|c|c|}
\hline Variables & Mean $\pm S D$ & Standard Error & Skewness & Kurtosis \\
\hline Stress & $5.20 \pm 7.59$ & 0.025 & 0.48 & -0.72 \\
\hline Depression & $6.78 \pm 6.29$ & 0.030 & 0.79 & -0.57 \\
\hline Social functioning & $10.37 \pm 3.98$ & 0.019 & 0.07 & -0.35 \\
\hline Physical scale & $7.26 \pm 3.46$ & 0.016 & 0.71 & 0.09 \\
\hline Self-esteem & $3.70 \pm 5.61$ & 0.027 & -0.71 & -0.57 \\
\hline Sleep quality & $5.44 \pm 2.86$ & 0.14 & 0.74 & 0.46 \\
\hline Body image dissatisfaction & $46.98 \pm 17.04$ & 0.83 & 0.49 & -0.46 \\
\hline Impaired social functioning & $21.58 \pm 7.77$ & 0.37 & 0.28 & -0.76 \\
\hline Physical activity & $14.88 \pm 4.79$ & 0.23 & 0.62 & -0.13 \\
\hline Academic performance & $42.5 \pm 8.12$ & 0.39 & -0.28 & -0.26 \\
\hline
\end{tabular}


Table 3. Matrix of correlation coefficients for the relationships between research variables

\begin{tabular}{|c|c|c|c|c|c|c|c|c|c|c|}
\hline$\frac{\underline{y}}{\frac{0}{0}}$ & 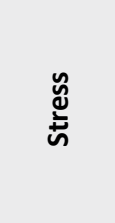 & $\begin{array}{l}\frac{5}{y} \\
\frac{0}{0} \\
\frac{0}{d}\end{array}$ & 조을 & 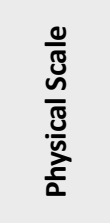 & 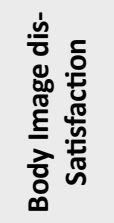 & 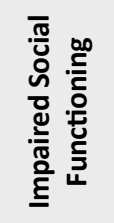 & 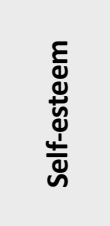 & $\begin{array}{l}\frac{z}{\frac{I}{\pi}} \\
\frac{0}{0} \\
0 \\
\frac{0}{0} \\
\frac{0}{n}\end{array}$ & 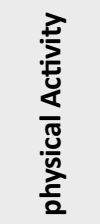 & 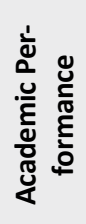 \\
\hline Stress & 1 & & & & & & & & & \\
\hline Depression & $0.671^{*}$ & 1 & & & & & & & & \\
\hline $\begin{array}{c}\text { Social } \\
\text { functioning }\end{array}$ & $-0.368^{*}$ & $-0.458^{*}$ & 1 & & & & & & & \\
\hline Physical scale & $0.641^{*}$ & $0.457^{*}$ & $-0.157^{*}$ & 1 & & & & & & \\
\hline $\begin{array}{l}\text { Body image dis- } \\
\text { satisfaction }\end{array}$ & $0.414^{*}$ & $0.471^{*}$ & $-0.387^{*}$ & $0.302^{*}$ & 1 & & & & & \\
\hline $\begin{array}{l}\text { Impaired social } \\
\text { functioning }\end{array}$ & 0.384 & $0.388^{*}$ & $-0.237^{*}$ & $0.348 *$ & $0.705^{*}$ & 1 & & & & \\
\hline Self-esteem & $-0.540 *$ & $-0.704^{*}$ & $0.554^{*}$ & $-0.376^{*}$ & $-0.566^{*}$ & $-0.377^{*}$ & 1 & & & \\
\hline Sleep quality & $0.572^{*}$ & $0.483^{*}$ & $-0.320 *$ & $0.510^{*}$ & $0.315^{*}$ & $0.307^{*}$ & $-0.405^{*}$ & 1 & & \\
\hline physical activity & -0.90 & $-0.137^{*}$ & $0.276^{*}$ & -0.031 & -0.091 & -0.086 & $0.187^{*}$ & $-0.130 *$ & 1 & \\
\hline $\begin{array}{l}\text { Academic per- } \\
\text { formance }\end{array}$ & $-0.466^{*}$ & $-0.523^{*}$ & $0.452^{*}$ & $-0.329^{*}$ & $-0.452^{*}$ & $-0.325^{*}$ & $0.550^{*}$ & $-0.303^{*}$ & $0.183^{*}$ & 1 \\
\hline
\end{tabular}

Table 4. Standardized coefficients of direct, indirect, and overall effects of variables in the structural equation model developed for participating students

\begin{tabular}{cccc}
\hline Model Variables & Direct Effect & Indirect Effect & Overall Effect \\
\hline Physical activity $\rightarrow$ Academic performance & $0.08^{*}$ & $-0.041^{*}$ & 0.039 \\
Self-esteem $\rightarrow$ Academic performance & $0.412^{* *}$ & $0.142^{* *}$ & 0.554 \\
Sleep quality $\rightarrow$ Academic performance & -0.064 & $-0.166^{* *}$ & -0.230 \\
\hline Body image dissatisfaction $\rightarrow$ Academic performance & $-0.185^{* *}$ & $-0.057^{* * *}$ & -0.242 \\
\hline General health $\rightarrow$ Academic performance & $-0.429^{* *}$ & -0.429 \\
Physical activity $\rightarrow$ General health & $-0.096^{*}$ & -0.096 \\
Self-esteem $\rightarrow$ General health & $-0.330^{* *}$ & -0.330 \\
Sleep quality $\rightarrow$ General health & $0.386^{* *}$ & 0.386 \\
\hline Body image dissatisfaction $\rightarrow$ General health & $0.133^{* * *}$ & & 0.133 \\
\hline $\mathrm{R}^{2}$ of the model & 0.355 & & \\
\hline
\end{tabular}

${ }^{*} \mathrm{P}<0.05 ;{ }^{* *} \mathrm{P}<0.01 ;{ }^{* * *} \mathrm{P}<0.001$

AJNPP

$(P<0.001)$. The direct effect of sleep quality on academic performance was negative and also smaller than the indirect effect. The indirect effect of sleep quality on academic performance through the mediation of general health was statistically significant $(\beta=-0.166, P<0.001)$. Body image dissatisfaction directly $(\beta=-0.185)$ and indirectly $(\beta=-0.057)$ affected academic performance and also general health had a direct effect on academic per- formance $(\beta=-0.057, P<0.001)$. In the developed structural equation model, body image, physical activity, general health, self-esteem, and sleep quality accounted for $35 \%$ of the variance in academic performance (Table 4). The direct and indirect effects of variables associated with academic performance are illustrated in Figure 2. 


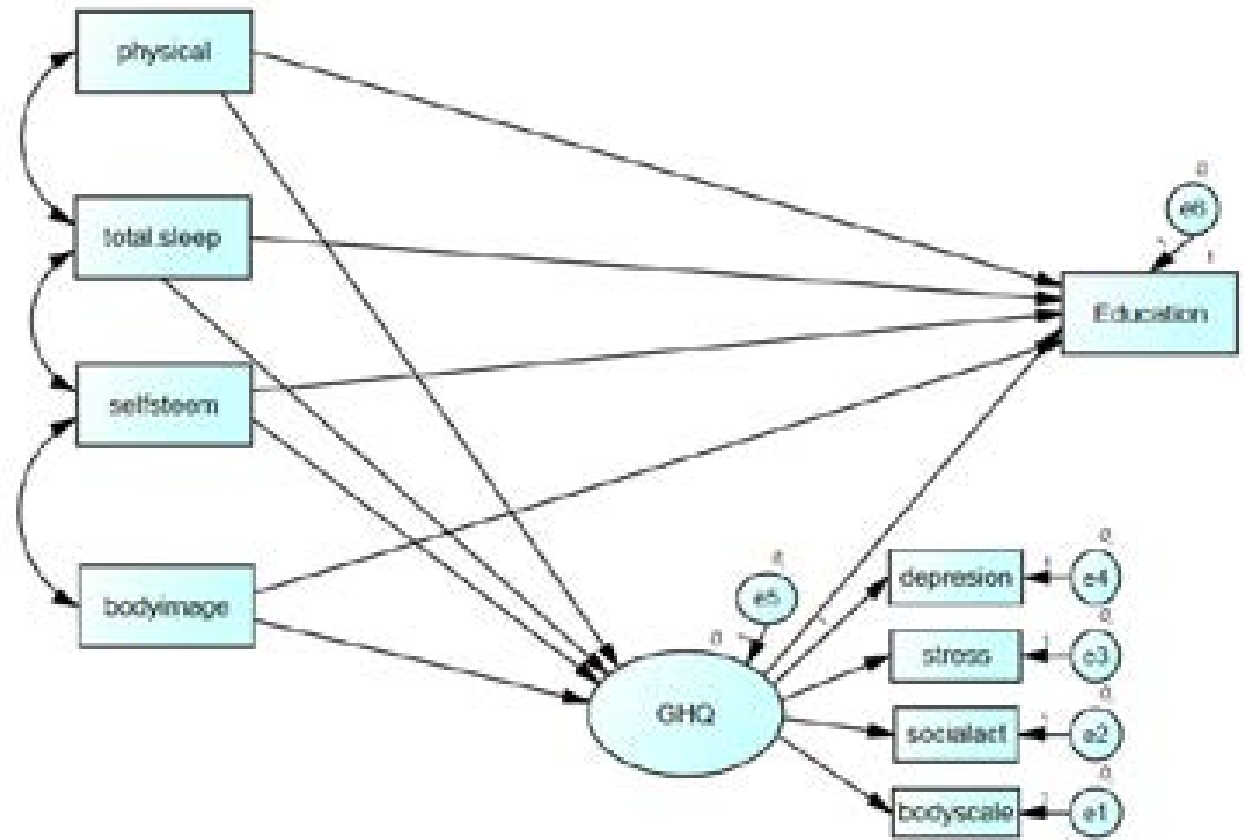

Figure 1. Conceptual model of the factors associated with academic performance in overweight and obese girl students

\section{Discussion}

To the best of the authors' knowledge, this was the first study in Iran to evaluate the effect of self-esteem, body image, mental health, physical activity, and sleep quality on the academic performance of obese or overweight female students using SEM. The results of this study showed that students' self-esteem had both direct and indirect effects (through general health) on their academic performance, with direct effects being stronger. In line with this result, numerous studies have shown that higher levels of self-esteem are associated with better academic achievements [33-36] and affect self-esteem and depression symptoms [37], indicating the mediating role of general health in this relation. Some studies have found no association between selfesteem and academic performance or have found them to be negatively correlated [38, 39]. However, different results can be achieved by considering their indirect relationships and the role of general health.

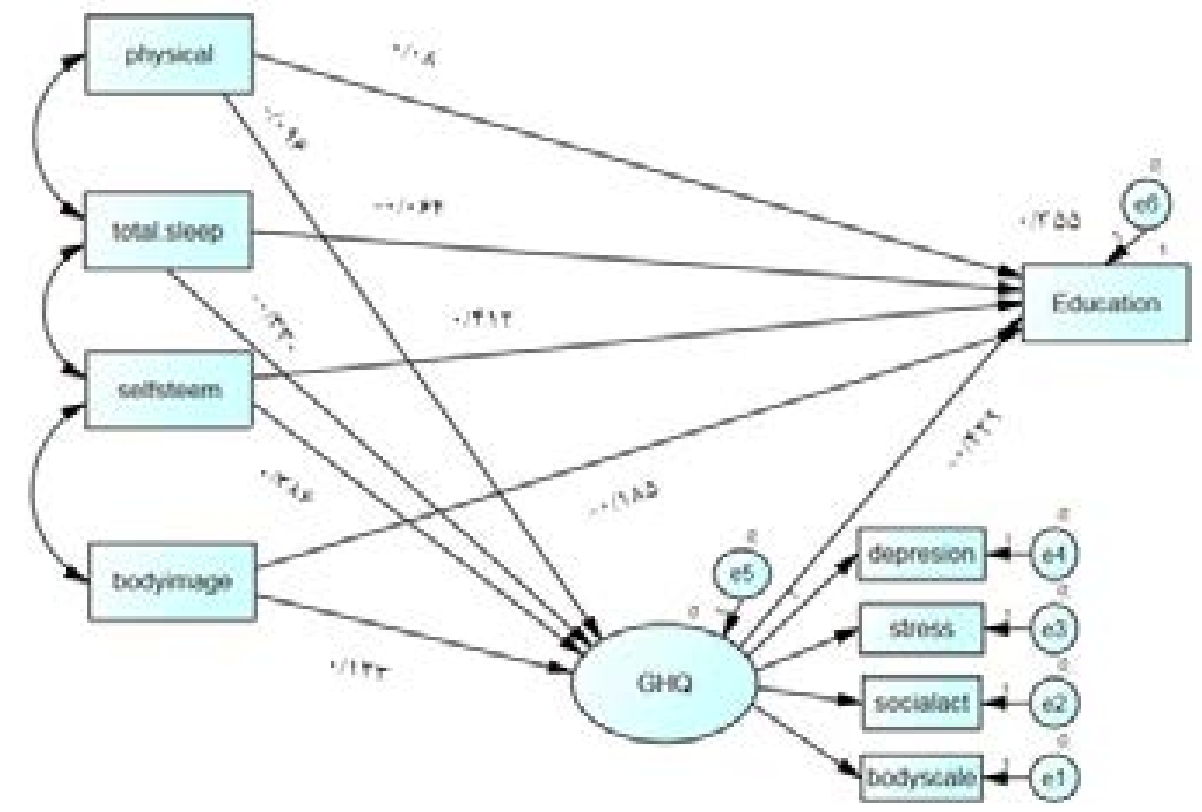

AJNPP

Figure 2. Structural equation model of the factors associated with academic performance in obese and overweight girl students 
Low self-esteem is considered a risk factor for aggression, depression, poor academic performance, etc. [40]. To explain these findings, it can be stated that self-esteem is one of the determinants of human behavior [41] and acts as the core of psychological structures that protect the person against psychological stress. A person with a high sense of self-worth can easily cope with external stressors without experiencing negative emotions [42].

In the present study, it was observed that physical activity increased academic performance both directly and indirectly (through general health). This is consistent with the findings of Coe et al. [43] and Chen et al. [44] studies, in which students who participated in physical activities had significantly higher grades than those whiteout physical activities.

To explain this relation, it can be argued that given the effect of physical activity and exercise on physical and mental wellbeing, and generally on general health, they positively affect the person's self-perception, self-esteem, and self-confidence and reduce the extent people are affected by physiological pressures and stress. This effect leads to an increase in learning and productivity and mental abilities development, which ultimately positively affects academic achievement [45].

Reduced self-esteem, body image dissatisfaction, social exclusion, and isolation are the consequences of obesity [8], which can affect the adolescent's social functioning. The results of this study showed a significant direct relationship between general health and dissatisfaction with body image. This is consistent with the findings of a study by Soltani, in which body image was positively correlated with mental health [46]. To explain this relationship, it can be argued that anxiety, stress, and psychological stress are among the most important causes of obesity in children and adolescents. Anxiety disorders lead to emotional eating, which is associated with obesity, and also lower mental health levels can predict one's BMI. Higher BMI is associated with more negative body image in girls [47].

People with a high BMI are dissatisfied with their body image. In adolescents, this dissatisfaction often leads to dissatisfaction with the body, which can result in depression and anxiety disorders. It has shown that multiple dimensions of body image are associated with academic underperformance. Among these dimensions, concerns about height and weight have the strongest effect on the relationship between body image and academic achievement. The results of the present study also confirmed these findings, as body image dissatisfaction had negative direct and indirect effects on academic performance.
We found sleep quality with significant direct and indirect effects on academic performance, because as sleep quality increases (its score decreases), mental health increases as well, leading to improved academic performance. This finding is in line with the findings of Zang et al. (2017), who reported that poor sleep quality was associated with an increase in mood disorders, anxiety, behavioral disorders, and poor perceived physical health [48]. In a study by Pavia, adolescents with sleep deprivation had more frequent health complaints and complaints about health and physical pain were significantly more frequent among girls than boys [49]. Poor sleep quality affects learning capacity and academic performance [50, 51]. Sleep is a basic human need and essential for preserving and maintaining energy and physical well-being. During sleep, hormones, such as norepinephrine, serotonin, and growth hormones are secreted, which trigger changes in chemical reactions and cellular nutrition that prepare the body for the resumption of activity [52]. People with sleep disorders experience not only fatigue but also defects in cell repair, difficulty in thinking, memorizing, and learning, and increased stress. Insomnia causes hormonal, behavioral, and physical disorders [53] because the brain processes information during the night's sleep, and it affects the physical, affective, and cognitive functions of the person throughout the day $[24,50,51]$.

The results of this study showed mental health with a strong statistically significant direct relationship with academic performance. Different aspects of mental health have widely shown linked to academic and learning performance. Depression in people with mental disorders is characterized by reduced energy and interest, a sense of guilt, difficulty concentrating, anorexia, and rumination about death, and suicide. It is also associated with changes in levels of physical activities, cognitive abilities, sleep condition, appetite, and other biological rhythms [54]. Depressed people have no motivation to pursue their goals. Depression in students causes them to think negatively and stop trying to make progress. Such negative behaviors lead to continued despair, which often leads to reduced academic performance [26]. People who experience emotional disturbances and impaired mental health for different reasons can exhibit them in different ways. These individuals often suffer from problems, such as poor self-concept, academic underperformance, social exclusion, inability to communicate with peers, and poor adherence to social rules, which have a direct impact on their learning process [25].

The present study had limitations, of which a large number of questions in used questionnaires resulted in 
fatigue and decreased the accuracy of the participants. The results of this study cannot be generalized to other age groups and male students.

\section{Conclusion}

This study found that self-esteem, body image, physical activity, and sleep quality affect the academic performance of obese and overweight students not only directly but also indirectly through general health. Therefore, to improve the academic performance of these students, special attention should be paid to their general health (mental health) and its dimensions.

\section{Ethical Considerations}

\section{Compliance with ethical guidelines}

Researchers respected all ethical requirements of research, such as gaining informed consent, assuring participants about the confidentiality of responses, and informing them about their right to end their participation at any stage of the research. This study was approved by the National Research Ethics Committee of Iran (Code: IR.IAU.KHUUISF.REC.1398.049).

\section{Funding}

This study was extracted from a PhD. thesis of first au thor in Department of Psychology, Isfahan (Khorasgan) Branch, Isfahan (Code: 23820702952015).

\section{Authors' contributions}

All authors contributed equally in preparing all parts of the research.

\section{Conflict of interest}

The authors declared no conflict of interest.

\section{References}

[1] Galani C, Schneider H. Prevention and treatment of obesity with lifestyle interventions: Review and meta-analysis. International Journal of Public Health. 2007; 52(6):348-59. [DOI:10.1007/s00038007-7015-8] [PMID]

[2] Khairy SA, Eid SR, El Hadidy LM, Gebril OH, Megawer AS. The health-related quality of life in normal and obese children. Egyptian Pediatric Association Gazette. 2016; 64(2):53-60. [DOI:10.1016/j. epag.2016.05.001
[3] Kouris-Blazos A, Wahlqvist ML. Health economics of weight management: Evidence and cost. Asia Pacific Journal of Clinical Nutrition. 2007; 16 Suppl 1:329-38.

[4] Dehghan M, Akhtar-Danesh N, Merchant AT. Childhood obesity, prevalence and prevention. Nutrition Journal. 2005; 4(1):24 [DOI:10.1186/1475-2891-4-24] [PMID] [PMCID]

[5] Aghapour B, Rashidi A, Dorosti-Motlagh A, Mehrabi Y. [The association between major dietary patterns and overweight or obesity among Iranian adolescent girls (Persian)]. Iranian Journal of Nutrition Sciences \& Food Technology. 2013; 7(5),289-98.

[6] Yu Z, Han S, Cao X, Guo X. Intelligence in relation to obesity: A systematic review and meta-analysis. Obesity Reviews. 2010; 11(9):656-70. [DOI:10.1111/j.1467-789X.2010.00792.x] [PMID]

[7] Li Y, Dai Q, Jackson JC, Zhang J. Overweight is associated with decreased cognitive functioning among school-age children and adolescents. Obesity. 2008; 16(8):1809-15. [DOI:10.1038/oby.2008.296] [PMID]

[8] Gunstad J, Spitznagel MB, Paul RH, Cohen RA, Kohn M, Luyster FS, et al. Body mass index and neuropsychological function in healthy children and adolescents. Appetite. 2008; 50(2-3):246-51. [DOI:10.1016/j.appet.2007.07.008] [PMID]

[9] Soleymanzadeh A, Shahrarai M. [The relationship between locus of control and self regulated learning with academic achievement (Persian)]. Journal of Psychology and Education. 2002; 31(2):175-98

[10] Serbin LA, Stack DM, Kingdon D. Academic success across the transition from primary to secondary schooling among lower-income adolescents: Understanding the effects of family resources and gender. Journa of Youth and Adolescence. 2013; 42(9):1331-47. [DOI:10.1007/s10964 013-9987-4] [PMID]

[11] Santana C, Hill J, Azevedo L, Gunnarsdottir T, Prado W. The association between obesity and academic performance in youth: A systematic review. Obesity Reviews. 2017; 18(10):1191-9. [DOI:10.1111/obr.12582] [PMID]

[12] Dale $H$, Brassington $L$, King $K$. The impact of healthy lifestyle interventions on mental health and wellbeing: A systematic review. Mental Health Review Journal. 2014; 19(1):1-26. [DOI:10.1108/MHRJ-05-20130016]

[13] Doaei S, Kalantari N, Majidi N, Malmir H. [Investigation of the association of body mass index with mental health and self-confidence in girls: A case-control study (Persian)]. Journal of North Khorasan University of Medical Sciences. 2018; 10(1):9-14.

[14] Ghamari F, Mohammadbeigi A, Mohammadsalehi N. [The association between mental health and demographic factors with educational success in the students of Arak Universities (Persian)]. Journal of Babol University of Medical Sciences. 2010; 12(1):118-24.

[15] Keong P, Sern L, Lee M, Ibrahim C, editors. The relationship between mental health and academic achievement among university students-a literature review. Second International Conference on Global Trends in Academic Research. 2015; 2:755-64.

[16] Abdel-Aziz EA, Hamza RT, Youssef AM, Mohammed FM. Health related quality of life and psychological problems in Egyptian children with simple obesity in relation to body mass index. Egyptian Journal of Medical Human Genetics. 2014; 15(2):149-54. [DOI:10.1016/j.ejmhg.2014.01.002]

[17] Sahebzamani M, Fesharaki M, Abdollahi Mofrad Z. [Association of life style and self-esteem among adolescent girls of daily public high schools of Tehran (Persian)]. Medical Sciences Journal. 2010; 20(1):45-51. 
[18] Smith PA, Shoho AR. Higher education trust, rank and race: A conceptual and empirical analysis. Innovative Higher Education. 2007; 32(3):125-38. [DOI:10.1007/s10755-007-9042-z]

[19] Cash TF. Body image: Past, present, and future. Body Image. 2004; 1(1):1-5. [DOI:10.1016/S1740-1445(03)00011-1]

[20] Tallat N, Fatima A, Fiza K, Adiya D. Body's image concerns and its impact on academic achievements. Journal of Psychology and Clinical Psychiatry. 2017; 7(3):1-5. [DOI:10.15406/jpcpy.2017.07.00437]

[21] Elsherif ZAE, Abdelraof ASE. The Relation between body image satisfaction, self-esteem and the academic behavior among the first and fourth year students in the faculty of nursing Tanta University. Clinical Nursing Studies. 2018; 6(3):28-38. [DOI:10.5430/ cns.v6n3p28]

[22] Chaddock L, Pontifex MB, Hillman $\mathrm{CH}$, Kramer AF. A review of the relation of aerobic fitness and physical activity to brain structure and function in children. Journal of the International Neuropsychological Society. 2011; 17(6):975-85. [DOI:10.1017/ S1355617711000567] [PMID]

[23] Chaddock L, Erickson KI, Prakash RS, VanPatter M, Voss MW Pontifex MB, et al. Basal ganglia volume is associated with aerobic fitness in preadolescent children. Developmental Neuroscience. 2010; 32(3):249-56. [DOI:10.1159/000316648] [PMID] [PMCID]

[24] Curcio G, Ferrara M, De Gennaro L. Sleep loss, learning capacity and academic performance. Sleep Medicine Reviews. 2006; 10(5):323-37. [DOI:10.1016/j.smrv.2005.11.001] [PMID]

[25] Sivertsen B, Glozier N, Harvey AG, Hysing M. Academic performance in adolescents with delayed sleep phase. Sleep Medicine. 2015; 16(9):1084-90. [DOI:10.1016/j.sleep.2015.04.011] [PMID]

[26] Soufi S, Sadri Damirchi E, Sedghi N, Sabayan B, Development of structural model for prediction of academic achievement by global self-esteem, academic self-concept, self-regulated learning strategies and autonomous academic motivation. Procedia - Social and Behavioral Sciences. 2013; 18(10):103-26.

[27] Mohammadi N. [Preliminary examination of validity and reliability of rosenberg's self-esteem scale of evolutionary psychology (Persian)]. Developmental Psychology: Iranian Psychologists. 2005; 4:55-62.

[28] Salmani K, Amini HA, Bayatpor M, Fazell-Kalkhoran J, Salehi M [The relationship between body image and body mass index with mental health in the course of development (Persian)]. Quarterly Journal of Child Mental Health. 2017; 4(3):3-15.

[29] Mohammadian H, Eftekhar H, Taghdisi MH, Mousavi GA, Sabahi M. [Validation of psychometric properties of Persian species of HPLP II life style questionnaire (Persian)]. Payeshjournal. 2013; 12(2):167-76.

[30] Nejat S, Montazeri A, Holakouie Naieni K, Mohammad K, Majdzadeh S. [The World Health Organization quality of Life (WHOQOLBREF) questionnaire: Translation and validation study of the Iranian version (Persian)]. Journal of School of Public Health and Institute of Public Health Research. 2006; 4(4):1-12.

[31] Saatchi M, Kamkari K, Asgarian M. Psychological tests. Tehran: Virayesh; 2012.

[32] Pahlavan Sharif S, Mahdavian V. Structural Equation Modeling with AMOS. Tehran: Bishe; 2015.

[33] Yang Q, Tian L, Huebner ES, Zhu X. Relations among academic achievement, self-esteem, and subjective well-being in school among elementary school students: A longitudinal mediation model. School Psychology Quarterly. 2019; 34(3):328-40. [DOI:10.1037/ spq0000292] [PMID]

[34] Marsh HW, Byrne BM, Yeung AS. Causal ordering of academic self-concept and achievement: Reanalysis of a pioneering study and. Educational Psychologist. 1999; 34(3):155-67. [DOI:10.1207/ s15326985ep3403_2]

[35] Booth MZ, Gerard JM. Self-esteem and academic achievement: A comparative study of adolescent students in England and the United States. Compare: A Journal of Comparative International Education. 2011; 41(5):629-48. [DOI:10.1080/03057925.2011.566 688] [PMID] [PMCID]

[36] Hosseini SN, Alavijeh MM, Matin BK, Hamzeh B, Ashtarian H, Jalilian $\mathrm{F}$. Locus of control or self-esteem; Which one is the best predictor of academic achievement in Iranian college students. Iranian Journal of Psychiatry Behavioral Sciences. 2016; 10(1):e2602. [DOI:10.17795/ijpbs-2602] [PMID] [PMCID]

[37] Humphrey N, Charlton JP, Newton I. The developmental roots of disaffection? Educational Psychology. 2004; 24(5):579-94. [DOI:10. 1080/0144341042000262926]

[38] Trautwein U, Lüdtke O, Köller O, Baumert J. Self-esteem, academic self-concept, and achievement: How the learning environment moderates the dynamics of self-concept. Journal of Personality Social Psychology. 2006; 90(2):334-49. [DOI:10.1037/0022-3514.90.2.334] [PMID]

[39] Tuliti Z. [Explaining the role of self-esteem and academic background in academic performance of university students in Tehran (Persian)]. Journal of Research in Educational Systems. 2011 5(12):109-25.

[40] Davari A, Yassaei S, Momeni Sarvestani M, Rahnama A. [Association between Self-esteem and Educational Status of Medical Students of Shahid Sadoughi University of Medical Sciences in Yazd (Persian)]. Yazd Journal of Dental Research. 2014; 3(2):262-71.

[41] Heydarpur S, Dokanehe Fard F, Bahari S. [The effect of effective communication skills training on increasing self-esteem and reducing low fitness of physical-mental disabilities in Tehran province (Persian)]. Quarterly Journal of New Thoughts in Educational Sciences. 2008; 3(4):41-52.

[42] Farida-Habib P, Haya ALFozan M, ABOG S, Najla-Barnawi M, Wojdan Al Motairi B. Relationship between body mass index, selfesteem and quality of life among adolescent saudi girl. Journal of Biology, Agriculture and Healthcare. 2015; 5(10).

[43] Coe DP, Pivarnik JM, Womack CJ, Reeves MJ, Malina RM. Effect of physical education and activity levels on academic achievement in children. Medicine Science in Sports Exercise. 2006; 38(8):1515-9. [DOI:10.1249/01.mss.0000227537.13175.1b] [PMID]

[44] Chen L, Fox KR, Ku PW, Taun CY. Fitness change and subsequent academic performance in adolescents. Journal of School Health. 2013; 83(9):631-8. [DOI:10.1111/josh.12075] [PMID]

[45] Beheshkehar F, Farahani A, Asadi H. [Comparison of the academic achievement of high school students participating in regular individual and group sports activities. Research in Sport Management (Persian)]. 2012; 1(2):117-36

[46] Soltani N, Safajou F, Amouzeshi Z, Zameni E. [The relationship between body image and mental health of students in Birjand in 2016 academic year: A short report. Journal of Rafsanjan University of Medical Sciences (Persian)]. 2017; 16(5):479-86. 
[47] Kantanista A, Osiński W, Borowiec J, Tomczak M, Król-Zielińska $\mathrm{M}$. Body image, BMI, and physical activity in girls and boys aged 14-16 years. Body Image. 2015; 15:40-3. [DOI:10.1016/j.bodyim.2015.05.001] [PMID]

[48] Zhang J, Paksarian D, Lamers F, Hickie IB, He J, Merikangas KR. Sleep patterns and mental health correlates in US adolescents. The Journal of Pediatrics. 2017; 182:137-43. [DOI:10.1016/j. jpeds.2016.11.007] [PMID]

[49] Paiva T, Gaspar T, Matos MG. Sleep deprivation in adolescents: Correlations with health complaints and health-related quality of life. Sleep Medicine. 2015; 16(4):521-7. [DOI:10.1016/j. sleep.2014.10.010] [PMID]

[50] Fallone G, Owens JA, Deane JR. Sleepiness in children and adolescents: Clinical implications. Sleep Medicine Reviews. 2002; 6(4):287-306. [DOI:10.1053/smrv.2001.0192] [PMID]

[51] Wolfson AR, Carskadon MA. Understanding adolescent's sleep patterns and school performance: A critical appraisal. Sleep Medicine Reviews. 2003; 7(6):491-506. [DOI:10.1016/S1087-0792(03)90003-7]

[52] Zakeri-Moghadam M, Shaban M, Kazemnejad A, Ghadyani L. [Comparison of effective factors on sleeping the nurses and hospitalized patients' viewpoints (Persian)]. Journal of Hayat. 2006; 12(2):5-12.

[53] AliMoradi F, Javadi M, Al-Qadr SJ, Avani A, Molodi J. [Importance of sleep and its relation with obesity, diet and diabetes (Persian)]. Sabzevar University of Medical Sciences. 2016; 24(1):35-41.

[54] Ildarabady E, Firouzkouhi MR, Mazloom S, Navidian A. [Prevalence of depression among students of Zabol Medical School, 2002 (Persian)]. Journal of Shahrekord Uuniversity of Medical Sciences. 2004; 6(2):15-21. 